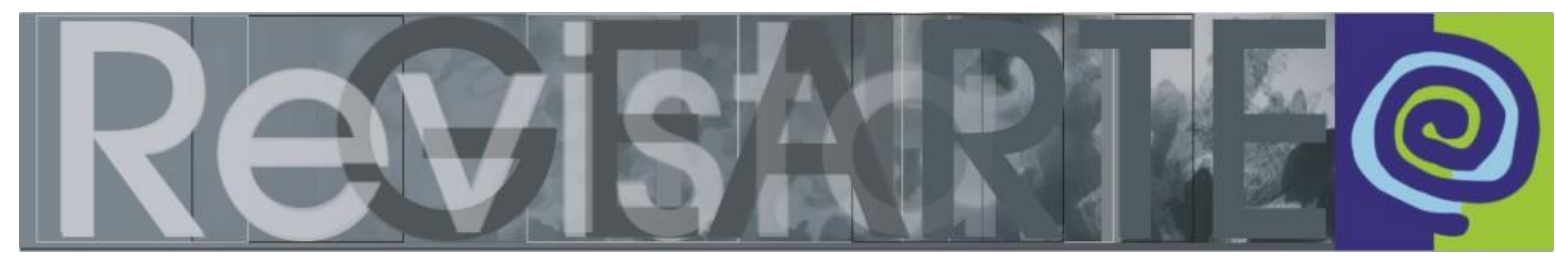

Volume 1, Número 1, Abril/2014, ISSN 2357-9854

\title{
O Teachers College e sua influência na modernização da educação no Brasil
}

\author{
Ana Mae Tavares Bastos Barbosa (USP e UAM - Brasil)
}

\begin{abstract}
RESUMO
A partir de uma pesquisa empreendida junto a documentos raros e arquivos do Teachers College, da Columbia University de New York, é possível verificar as influências exercidas por essa Instituição no ensino de arte dos Estados Unidos e sua relação com o Brasil desde o século XIX. Muitos pensadores que atuaram no TC e cujas ideias são referenciais na história da educação, contribuiram significativamente para o pensamento educacional das Américas, o que linclui o Brasil, entre eles podese destacar John Dewey. Algumas atividades epistolares de brasileiros que estudaram no TC são relatadas no decorrer do texto, de modo a elucidar aspectos da atuação de professores e alunos do Teachers College. Entre outras, na segunda metade dos anos 20, houve um significativo intercâmbio, conhecido como "Embaixada de Minas Gerais", que levou para o Teachers College cinco jovens professoras de Belo Horizonte. Cabe destacar aqui as percepções e impressões acerca da arte, de uma dessas alunas, Profa. Alda Lodi, obtidas através de entrevista, como também algumas cartas da jovem estudante Benedicta Valladares, diante da realidade vivenciada no Teachers College.
\end{abstract}

PALAVRAS-CHAVE

Ensino da Arte; Teachers College; Educação

\section{ABSTRACT}

It is possible to verify, from a research undertaken with the rare documents and files from Teachers College at Columbia University in New York, the influences exerted by this institution in the teaching of art in the United States of America and its relationship with Brazil since the nineteenth century. Many thinkers who worked in Teachers College and whose ideas are benchmarks in the history of education, contributed significantly to the educational thought of the Americas, among them we can mention John Dewey. Some epistolary activities of Brazilians who studied in Teachers College are reported throughout the paper, in order to elucidate aspects of the performance of teachers and students of Teachers College. Among others, in the second half of the twenties, there was a significant exchange, better known by "Embaixada de Minas Gerais", which led five young teachers from Belo Horizonte to Teachers College. It is worth mentioning here the perceptions and impressions about art, of one of these students, Professor Alda Lodi, obtained through interview, as well as, some letters from young student Benedicta Valladares, given the reality experienced at Teachers College.

\section{KEYWORDS}

Art Education, Teachers College, Education

"The transformation of society, at the heart of both feminism and socialism, will not take place until feminist strategies are acknowledged and fully integrated into the struggle [...]. There is I know a certain danger that when women's issues are expanded too far they will get swallowed up by amorphous liberalism".

(Lucy Lippard)

\section{A institucionalização do ensino da arte e do Desenho no Brasil se deu à margem} da colonização direta de Portugal. Éramos dominados pelos portugueses, mas fomos modelados pelos franceses. Aliás, no século XIX os portugueses de Lisboa 
reclamavam que o Brasil tinha um ensino da arte melhor que o deles próprios. Nosso ensino superior de arte esteve tanto tempo sob a tutela da França, que chegamos ao ponto de esquecermos a França e ficarmos apenas conservadores. Mas em relação ao ensino primário e secundário públicos seguimos mais diretamente o Instituto Jean Jacques Rousseau da Suíça, que era um dos líderes da Escola Nova; a Inglaterra e os Estados Unidos, através de Walter Smith, no que diz respeito à iniciação ao Design; e por fim o Teachers College da Columbia University de New York.

Como diz um dos documentos arquivados na sua biblioteca de livros e documentos raros, o Teachers College (TC) foi fundado em novembro de 1894, em frente a um asilo e um pasto de vacas e foi em pouco tempo incorporado à Columbia University.

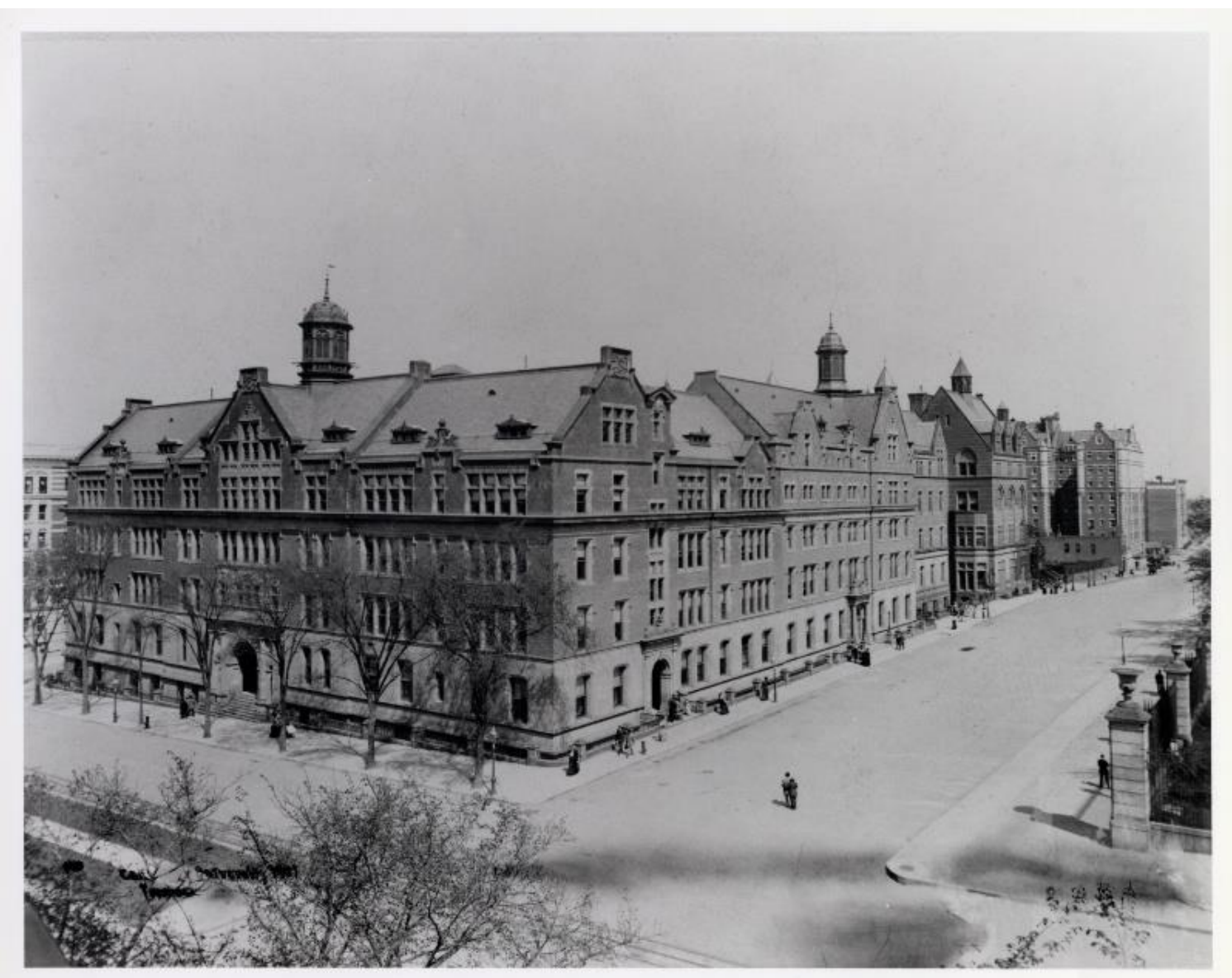

Figura 1 - Teachers College. Vista Sudoeste do edifício principal, 1907, fotógrafo desconhecido. Disponível em: <http://pocketknowledge.tc.columbia.edu/home.php/ gallery_singleimage?pid=1\&number=366\&order=date\&pagenum $=2>$.

Duas mudanças estavam ocorrendo em educação: 
1) A educação popular estava se desenvolvendo, aumentando de 9.900.000 estudantes em 1880, para 12.700 .000 em décadas depois;

2) A taxa de analfabetismo tinha baixado de $17 \%$ em 1880 , para $11 \%$ na virada do século.

As Faculdades (Colleges) de Educação Superior eram 350 em 1880 e 500 em 1890. A coeducação se desenvolvia. Em 1886 a primeira mulher foi contratada como inspetora escolar de New York.

Os fundadores do TC foram Grace Hoadley Dodge, filantropista executiva de empresas e feminista; Nicholas Murray Butler, filósofo e estudioso de educação, que defendia especial treinamento para professores; James E. Russell, reformador da educação e designer da educação profissional, que assumiu o papel de primeiro Diretor do TC.

A criação do Teachers College evoluiu de um processo iniciado e liderado por Grace Dodge, que criou a Working Girls Society; a YWCA (Young Women's Christian Association); a Travelers Aid para expansão da cultura e proteção das mulheres pobres; e finalmente a Industrial Education Association (IEA), que rapidamente se transformou no New York College for the Training of Teachers e depois Teachers College. A IEA era comprometida com a capacitação principalmente das mulheres para as artes manuais e domésticas. Grace Dodge sentiu necessidade de formação mais ampla para professoras, e o contexto desenvolvimentista dos Estados Unidos na época tornou o Teachers College um empreendimento bem sucedido. A incorporação à Columbia University não foi difícil, pois a mulher de um importante mantenedor da Columbia University, Mary Nash Agnew, era amiga e companheira de lutas sociais de Grace Dodge. O prefeito William R. Grace nomeou as duas como membros do New York City Board of Education. Elas se tornaram as primeiras mulheres a ocupar esse cargo, e William Grace foi por três anos do Conselho do TC. Portanto, na base da criação do TC esteve o movimento feminista americano, no qual se envolveram mulheres ricas com fácil acesso ao poder dominado pelos homens. Elas usavam uma linguagem que associava um certo assistencialismo ao desenvolvimentismo, ambos aliados a uma ação política eficiente, uma política de resultados individuais, sociais, comerciais e industriais. 
Foram contratados por Russell os professores Paul Monroe - historiador da Educação lido até hoje - e Edward Lee Thorndike. Este último chegou em 1899, com 25 anos, e em cinco anos se tornou professor titular. Alguns o classificam como psicólogo behaviorista, mas eu acho mais adequado designá-lo como psicólogo da aprendizagem. Fez seu doutorado na Columbia, mas antes fora aluno de William James em Harvard. Foi um dos primeiros psicólogos a usar animais nas pesquisas.

John Dewey foi convidado entre 1904 e 1906, como professor de filosofia da educação. Foi primeiro membro da Faculdade de Filosofia na Columbia e desde 1900 também integrava o grupo de professores da Faculdade de Educação. Estava em posição de influenciar o TC. Mais tarde, quando o departamento de Educacional Research foi estabelecido no TC foi um dos sete professores contratados em primeiro lugar. O discípulo dele, Kilpatrick, foi contratado em 1913.

No currículo havia Domestic Arts, Art Education em Museus e Voice Training em Educação Física. Pelas cartas e projetos que li na biblioteca de documentos raros do TC, pude entender que seus criadores tinham a missão de educar não só os americanos, mas que já começaram com o propósito de influir internacionalmente na Educação das outras Américas.

Uma carta de cinco de novembro de 1915 de Arthur Brown do Committee on Cooperation in Latin America convida o Diretor do TC, Prof. James Russell, para integrar um grupo que realizaria um Congresso de Educação no Panamá, de 10 a 20 de fevereiro, e conferências em Lima, Santiago, Buenos Aires e Rio de Janeiro, ficando oito dias em cada cidade. Esse Committee representava a Agência de Missionários em trabalho nas Índias Ocidentais, México, América do Sul e Central. Acompanhando a carta, enviou também um documento de 12 páginas datilografadas explicando os objetivos do trabalho de educação na América Latina, que resumidamente eram: conversão de alunos, treinamento de líderes nativos para a Igreja e influenciar na vida da comunidade em direção à difusão do cristianismo. $O$ documento traz uma análise histórica das universidades de São Marcos (1551) no Peru, reconhecendo-a como a mais antiga, criada 87 anos antes da Universidade de Harvard, e lembrando que mesmo a mais nova das importantes universidades da América Latina, a de Santiago (1838), era mais velha que a maioria das instituições de ensino norte americanas. Mas, critica todo o sistema latino americano de ensino 
como dogmático, cujo primeiro objetivo era fazer os homens submissos à Igreja Católica e ao Estado. O que queriam era trocar uma religião por outra, e despendiam esforços para isso. A viagem duraria ao todo 84 dias, dos quais 44 no navio.

Respondendo a essa carta, Russell escreve ao Secretário do Committee, Rev. S. G. Inman, em 30 de novembro de 1915. Ele não menciona o convite para acompanhar a Missão à América Latina, mas elogia o documento recebido, que realmente era historicamente detalhado. Entretanto, Russell delicadamente exprime sua ideia de que uma educação missionária deveria ser em "todo lugar": treinar para a cidadania contribuindo para a estabilidade política. Fica subentendido que se opunha ao estreito objetivo de formatar para esta ou aquela religião. Diz ele na carta: "O melhor serviço que o movimento missionário evangélico pode prestar em minha opinião é disseminar ideais democráticos"1. Termina sugerindo que o documento inclua comentários sobre o Movimento de Escoteiros como uma força em direção à boa cidadania.

Russell não acompanhou essa expedição "civilizatória" porque se operou do apêndice. Pelo menos essa foi a desculpa. Os objetivos internacionais do TC eram mais amplos, menos religiosos e mais científicos.

Em Art Education, Arthur Dow era a estrela do TC e um dos mais famosos professores dos Estados Unidos até 1922, ano em que morreu. Suas cartas burocráticas de agradecimento e de pedidos são sempre especiais e incluem reflexões sobre conceitos ou questionamentos. Numa das cartas defende a arte na escola pública porque atinge a todos os cidadãos, e dá muita importância ao Desenho a mão livre por seu valor para a educação geral. Em outra, agradece as bolsas (grants) em alguns cursos para promover a instrução nas artes, dizendo que produzirão bons resultados para elevar o gosto estético de uma sociedade favorecida. Portanto, se interessava em ampliar os horizontes estéticos dos cidadãos comuns e dos ricos também.

Às vezes era irônico. Uma carta de Arthur Dow, de 13 de Janeiro de 1920, para Dr. Russell, o diretor do TC, diz: "Uma neta de Abraham Lincoln quer entrar numa

\footnotetext{
1 Carta datilografada encontrada nos arquivos de documentos raros do Teachers College .30 de novembro de 1915.
} 
classe de brancos para estudar fotografia. Ela está agora num estúdio de cinema no centro (downtown), área que vai deixar porque há 'gente de cor demais'. How is that for a Lincoln story!?"2, questiona Dow.

Não conheço a história de New York, mas o curioso é que downtown, que inclui Greenwich Village e Wall Street, não é hoje área dos afrodescendentes. O Harlem, muito próximo ao TC, é que o é.

Arthur Dow valorizava a expressão livre da criança pequena, mas propunha exercícios de composição baseados em: linha, notan, e cor para os maiores.

Notan é um termo japonês usado para descrever as nuances de claro e escuro nas cores, e não somente no preto e branco, embora Dow fosse muito interessado nos graus de cinza. Para o pesquisador japonês Akio Okasaki ${ }^{3}$, quem melhor definiu notan, ao analisar os métodos de Dow foi Robert Saunders (1966) que disse: "Por 'notan', ele [Dow] significava o balanço da luz e da escuridão do objeto quer fosse um edifício, uma pintura ou a natureza. O termo 'notan' significa mais que o termo 'valor' como elemento do design moderno na Alemã Bauhaus. Ele [Dow] cuidadosamente acrescentava dois hifens para traduzir "notan": Dark-and-Light"4. Também não se pode reduzir notan à relação luz e sombra - um fenômeno da natureza, enquanto notan se refere à visualidade construída. Dow foi aluno de Ernst Fenolosa, especialista e colecionador de arte japonesa que dirigiu o Departamento de Arte Oriental do Museu de Arte de Boston, para o qual doou sua coleção. Fenolosa passou alguns anos no Japão como professor de filosofia política na Tokio Imperial University. Ele influenciou os próprios japoneses a voltarem a considerar, ensinar e valorizar a arte do Japão nas escolas num período de excessiva ocidentalização. Haroldo de Campos era um admirador de Fenolosa e tinha todos os seus livros. Tive boas conversas com ele sobre a recusa de Fenolosa ao naturalismo como base do ensino da arte, ideia que ele substituía pelo domínio da estrutura do que se via e do que se fazia.

\footnotetext{
${ }^{2}$ Carta datilografada encontrada nos arquivos de documentos raros do Teacher College . 13 de Janeiro de 1920

3 OKASAKI, 1999, p. 5.

${ }^{4}$ SAUNDERS, 1966, ps. 1-48.
} 
Prometi a Haroldo que iria escrever sobre Fenolosa como influenciador do ensino da arte nos Estados Unidos e no Japão, mas outros interesses se impuseram. Haroldo me cobrava frequentemente o estudo sobre Fenolosa.

Em carta de 17 de novembro de 1915, Dow pede ao Diretor Russell para comprar a coleção de slides de Fenolosa. Diz que a mulher de Fenolosa enviara a coleção de 1.200 slides para ele examinar. Tratava-se de slides fotografados em museus e coleções particulares por especialistas, e muitos fotografados pelo próprio Fenolosa. Ele propõe que se paguem duzentos dólares por toda a coleção que, segundo ele, valeria 800 dólares. Lamenta não poder comprá-la pessoalmente e argumenta contra a possibilidade de se desmembrar a coleção, demonstrando respeito pela história cultural de um historiador da arte e de uma época. Não consegui descobrir se a coleção foi comprada, nem se ainda existe.

Também importante como professora de Art Education da Columbia University foi Belle Boas, que naquela época já questionava a hegemonia da Pintura e trabalhava com seus alunos não só com obras de arte, mas também com análise e produção de pôsteres comerciais. Belle Boas era diretora de Artes Visuais da Escola Horace Mann, escola de demonstração pedagógica do TC, quando publicou em 1926 seu livro Art in the $S c h o o / 5$ dedicado à memória de Arthur Dow.

No início do século XX o TC tornou-se rapidamente uma instituição de liderança no ensino da arte, não só graças a Dow, Dewey e Boas, mas muitos professores contribuíram para isso, assim como ex-alunos que não fincaram seus nomes na História. Margaret Mathias, por exemplo, ex-aluna de Art Education do TC, espalhou a ideologia de seus mestres quando foi supervisora do sistema escolar.

$\mathrm{Na}$ base dos ensinamentos de todos estava a ideia de que era preciso fazer arte e apreciar também. Mathias colocava o problema da seguinte maneira:

Se nós esperamos construir uma sociedade com apreciação de arte e alguma habilidade para resolver problemas de Arte, um curso de arte adequado deve proporcionar o desenvolvimento da habilidade de auto-expressão e de entender a expressão dos outros (MATHIAS, 1924, p. 01).

${ }^{5}$ BOAS, 1926. 
O interessante é que desde cedo o TC se preocupou em organizar cursos extracurriculares de educação em museus, que chamavam de Museum Guidance, com um professor chamado Cornell, que era muito elogiado (segundo um pedido de repetição do curso que encontrei). Cobravam doze dólares pelo curso, mas não descobri a duração. Havia cursos avulsos de lettering - algo que poderia ser definido como desenho caligráfico que às vezes incluía design gráfico, mas privilegiava o traçado manual de letras. Miss Tannahill dava outro curso avulso de Color Print para criação de cartazes.

Para atuar internacionalmente o TC procurou estabelecer convênios com instituições mais poderosas economicamente, como a Carnegie Corporation.

Uma carta de 20 de abril de 1927, de Russell dirigida a Carnegie Corporation of New York, agradece o apoio econômico dado aos cursos de artes no TC e pede financiamento para estender os conhecimentos e a formação em arte educação do TC para todo o país e outros países também. Chama a atenção para a importância da educação estética para a sociedade, não só para estimular criadores desde a infância, mas também para formar os consumidores ameaçados pela produção em massa.

Provavelmente teve sucesso, porque dois anos depois o Jornal do Brasil de 05 de julho de 1929 publicou uma entrevista com Delgado de Carvalho sobre a ida de professores brasileiros para os Estados Unidos, na qual ele dá a entender que a Columbia University recebia subvenções da Carnegie Corporation, a qual se dispôs a por nossos professores em contato com o Teachers College. Eis parte da entrevista:

Jornal do Brasil -05 de julho de 1929

AMPLIANDO OS HORIZONTES DA NOSSA CULTURA.

A Associação Brasileira de Educação está cogitando de enviar anualmente 10 professores brasileiros para visitar as universidades americanas - diz-nos em entrevista, o professor Delgado de Carvalho.

Um oferecimento da Carnegie Endowement.

E o professor Delgado de Carvalho, na sua conversa fluente e despretensiosa, prossegue:

- mais do que nunca, durante a minha recente excursão aos Estados Unidos, lembrei-me de trabalhar para que os nossos professores pudessem enxergar o que eu estava vendo e observando nos museus e nas Universidades americanas. E veio-me a ideia de apelar para a famosa filantropia americana. Indaguei daqui, dali, e procurei me aproximar das instituições subvencionadas pela Carnegie Endowement, como a União Pan-Americana, o Instituto Internacional de Educação e a Universidade de Columbia. Ciente dos caminhos a seguir, escrevi um ofício àquela Fundação sugerindo um convite aos professores brasileiros para visitarem os Estados Unidos durante 
as suas férias, permitindo-Ihes ver o que lá existe em condições de auxiliar cada qual no aperfeiçoamento de sua especialidade.

A resposta à minha sugestão, que era feita em nome da $A B E$ (Associação Brasileira de Educação) - e tenho muito orgulho em recordar que fui seu primeiro presidente - não podia ser resolvida senão depois de determinada assembleia anual que se realizaria em maio, dois meses, portanto, após o meu regresso. Ela foi aceita na época oportuna, conforme me informou em carta o doutor Rowe, diretor da União Pan-americana; a Carnegie Endowement se propondo a facilitar a visita de 10 professores brasileiros aos estabelecimentos que mais lhe possam interessar nas cidades do Atlântico, custeando-Ihes a estadia nos Estados Unidos durante 5 semanas e os pondo, finalmente, em contato com os professores do Teachers College da Universidade de Columbia para trocar impressões e eliminarem quaisquer dúvidas. Os dez professores que gozariam destas vantagens seriam indicados pela $A B E$.

Um oferecimento da Associação Nacional de Educação.

Um segundo oferecimento gentil partiu da Associação Nacional de Educação de Washington instituição que conta com mais de 200 mil associados, a qual tomará sobre sua acolhida os enviados da ABE servindo-lhes de guia.

As condições para a visita nos Estados Unidos.

O oferecimento da Carnegie Endowement é somente para o próximo ano.

É certo, porém - insinua o professor Delgado - que diante de um resultado feliz deste primeiro ensaio, o convite se repetirá todos os anos.

Atendendo a isso, é sugestão contida na carta do Sr. Rowe, de se escolher somente dois ou três subgrupos de assuntos para não dispersar esforços; o conselho diretor da ABE acaba de votar a regulamentação para a ida dos professores aos Estados Unidos no próximo mês de janeiro, ficando aberta na sua sede as inscrições para os que desejarem se aproveitar desta excursão. A inscrição irá até 30 de setembro e logo depois de encerrada uma comissão nomeada "ad hoc" pelo Conselho Diretor, escolherá de acordo com as credenciais apresentadas, dez nomes de professores, os quais deverão estudar determinados assuntos e entregar na sua volta um relatório à $A B E$. As despesas da viagem marítima.

Não custeando a Carnegie Endowement senão as despesas de estadia nos Estados Unidos, fui procurar o Senhor Frank Mumson, diretor da "Mumson Line" e pedir-Ihe um abatimento nas passagens em seus navios para estes professores. O sr. Mumson não me deu ainda uma resposta definitiva, mas tenho comigo a certeza que ele se decidirá a grande redução pedida, como ele acaba de conceder aos estudantes americanos embarcados em Nova York na semana passada e que vem estudar cousas brasileiras (CARVALHO, 1929).

\section{Os intercâmbios entre professores continuaram, pois no ano seguinte um artigo} do Diário de Notícias de 10 de julho de 1930 nos dá notícias da segunda visita de educadores norte-americanos ao Brasil.

Diário de Notícias - 10 de julho de 1930

A MELHOR APROXIMAÇẪO ENTRE O BRASIL E OS ESTADOS UNIDOS Chega hoje à noite, pelo "Western World" a segunda turma de professores norte-americanos

Uma feliz iniciativa do nosso Instituto Histórico e Geográfico em combinação com o Institute of International Education, de Nova York, iniciou, no ano passado, um proveitoso intercâmbio de professores entre os Estados Unidos e o Brasil, para cursos e estudos de assuntos especiais de cada país.

A primeira turma de professores norte-americanos aqui chegou, a 11 de junho de 1929 no "Southern Cross". Tão evidentes foram os resultados colhidos 
que, regressando à sua patria, eles fizeram as mais francas referências ao Brasil e aos brasileiros em todos os meios universitários.

Em novembro do mesmo ano, partiu do Rio o primeiro grupo de representantes do nosso magistério, cujo aproveitamento, na grande república, está sendo conhecido, desde meses, através de entrevistas, relatórios e conferências.

Vem agora a segunda turma norte-americana que deve desembarcar hoje, à noite, nesta capital tendo viajado no "Western World".

Constituem esse grupo os seguintes professores: Frank Spaulding, decano da Escola de Educação (instituto correspondente ao que se poderia chamar aqui de Escola Normal Superior), da Universidade de Yale; Umylsteker, especialista em línguas romanas: Victor Vray, da Universidade de Evanston; Miss Leeds Darnel da Universidade de Columbia; Miss K.Bott, da Escola Secundária de Central Falls; miss Slack, da Universidade de Evanston; miss Hatch, professora de História; miss Eckert e miss Baily, da Escola de Comércio de Gloucester (Estado de Massachussetts); e mrs. Miller, diretora de escola pública elementar.

O professor Frank Spaulding ${ }^{6}$ vem especialmente interessado em observar os nossos problemas didáticos.

Os cursos estão organizados de acordo com o seguinte programa: 1Evolução histórica do Brasil durante os séculos XIX e XX - pelo dr. Pandiá Calogeras; II-A atual situação econômica do Brasil, aspectos internacionais pelo dr. Carlos Delgado de Carvalho.

III- Desenvolvimento sociológico do povo brasileiro - pelo dr. Carneiro Leão; IV-Geografia física do Brasil; trabalhos dos geólogos americanos - pelo Dr. Arrojado Lisboa; V - Literatura brasileira, suas influências estrangeiras e tendências atuais - pelo Dr. Afrânio Peixoto.

Os cursos serão feitos em inglês, todas as manhãs, ficando as tardes livres para passeios e visitas dos professores às escolas, institutos, museus, etc (Diário de Notícias, 1930).

Mas, desde 1916 alunos brasileiros receberam diploma de Mestrado no Teachers College. Encontrei uma lista explícita e detalhada dos 20 brasileiros que concluíram mestrado no TC, de 1916 a 1956:

\author{
Alvarenga, Anyta - 1956 \\ Alves de Almeida, Isaias - 1931 \\ Ardayne, Júlia Collins - 1932 \\ Bruce, John Lee - 1916 \\ De Abreu, Maria José - 1954 \\ Dias, Lygia Siqueira C - 1955 \\ Chagas, Agnes Stewart Waddell - 1947 \\ Goes, Joaquim Faria - 1936 \\ Guimarães, Ignacia Ferreira - 1928 \\ Gorenstín, Fanny - 1948 \\ De Freitas, Mr Joseph Cursino - ? \\ Jardim, Lúcia - 1952 \\ Marshall, Simone Paulette - 1952 \\ Martins, Octavio A L - 1940 \\ Pinheiro, Maria Rosa Sousa - 1948 \\ Ribeiro, Marcia de C. Martins - 1947 \\ Scheeffer, Ruth Nobre - 1951 \\ Teixeira, Anisio Spinola - 1929
}

\footnotetext{
${ }^{6}$ Spauding era o mais importante deles. Publicava muito e muito se escrevia sobre ele. Era uma figura pública e poderosa.
} 
O primeiro mestre brasileiro formado pelo TC, em 1916, foi John Lee Bruce, de acordo com a lista acima. Pelo nome parece que era descendente dos americanos que se mudaram para o Brasil, muitos para São Paulo, outros para a Amazônia, depois da guerra de secessão norte-americana. Vários dos educadores brasileiros que fizeram mestrado no TC que constam dessa lista foram importantes no Brasil - como Celina Viegas, de São João Del Rei, em Minas Gerais, que viveu até os 110 anos, a maior parte deles trabalhando como educadora. A casa em que viveu, conhecida como Solar dos Viegas, foi tombada pelo Patrimônio Histórico ${ }^{7}$. Outra mineira, Ignacia Ferreira Guimarães foi personagem importante da educação em seu estado. Anísio Teixeira foi Ministro da Educação, criou universidades, foi perseguido no Estado Novo e na Ditadura Militar de 64. Ele foi um dos mais ativos e influentes educadores do Brasil. Sua estranha morte em um poço de elevador deixou dúvidas que tenha sido um homicídio político e não um mero acidente. Isaias Alves de Almeida especializouse em algo que estava muito na moda na época: os testes psicológicos e cognitivos. Trabalhou com Anísio Teixeira até que o Estado Novo os separou. Ambos eram baianos. Joaquim de Freitas Goés Filho ${ }^{8}$, que dirigiu o SENAI na Bahia de 1948 a 1960, continuou trabalhando com Teixeira até 1971, quando publicaram um pequeno e primoroso texto sobre a educação como proposta para a criação de um Centro de Estudos de Pós-Graduados de Educação na Fundação Getúlio Vargas (FGV) no Rio. A paulista Olga Verderese foi professora, mas já era enfermeira formada na segunda turma da Universidade de São Paulo quando fez seu mestrado no TC. Fundou a Associação Brasileira das Enfermeiras Diplomadas e foi muito influente no Ensino Universitário de enfermagem do Nordeste ao Sul do Brasil. Também professora da Escola de Enfermagem da USP, Maria Rosa de Sousa Pinheiro foi extremamente competente e engajada, impedindo a prisão de alunos durante a ditadura militar. Octavio A. L. Martins especializou-se em estatística de volta ao Brasil. Ruth Scheeffer

\footnotetext{
7 Processo no 018/2000. Notificados: Dr. Milton de Resende Viegas e outros. Objeto: tombamento voluntário do imóvel situado a Rua Dr. José Mourão, número 77 - Centro, São João Del Rei. Fonte: IPHAN. Relator: conselheiro José Antônio de Ávila Sacramento.
}

8 TEIXEIRA, A; GOÉS FILHO, 1971, p. 29. 
Nobre $^{9}$ foi professora em universidades no Rio, se dedicando principalmente à psicologia comunitária e a psicologia do adolescente. Outros foram bem sucedidos como escritores de ficção e poesia, enfim, a safra do TC trabalhou duro e melhorou a educação em várias áreas no Brasil, não só como professores, mas também como gestores.

Em um dos relatórios não assinados, consultados por mim na biblioteca de documentos raros do TC, há uma relação numérica dos alunos Latino Americanos no TC. Trata-se de alunos regulares de formação inicial ou undergraduated - como se chama nos Estados Unidos - não de alunos de mestrado ou de cursos de curta duração ou ainda de cursos especiais.

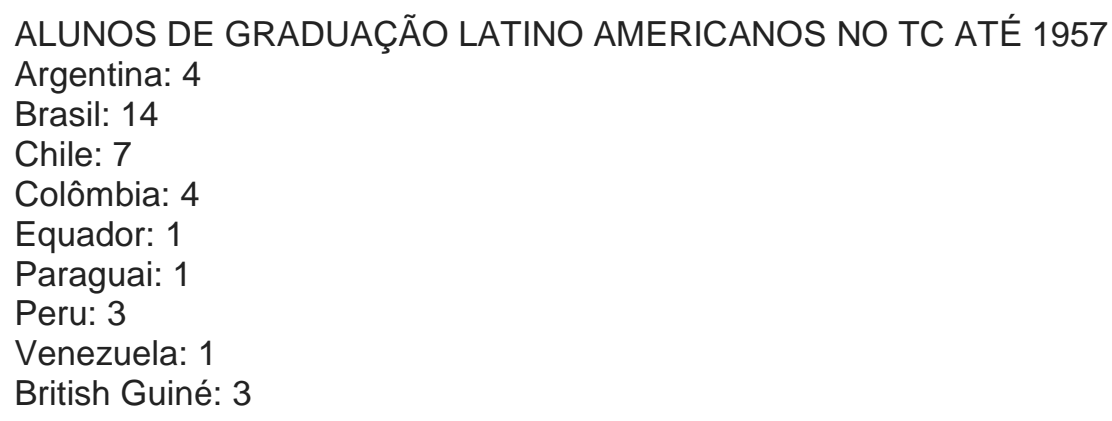

Numa outra lista de alunos estrangeiros até 1959, vemos que o número de alunos brasileiros aumenta em dois anos de 14 para 88. Essa última lista, entretanto, não especifica se são alunos de mestrado, de graduação ou ainda se inclui ambos.

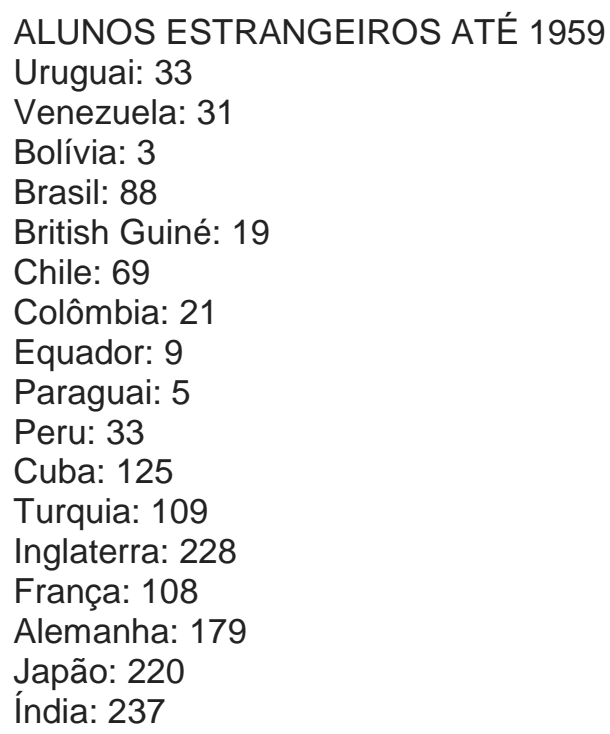

${ }_{9}$ NOBRE, Ruth Scheeffer. Curso de Noções de Psicologia da Adolescência. Rio de Janeiro: Fundação Getúlio Vargas. s/d. 
Filipinas: 426

Havaí: 489

Porto Rico: 684

Jamaica: 125

Como se pode ver, o número de estudantes dos países ocupados pelos americanos durante o pós-guerra é o maior. No Brasil, o intercâmbio com o TC mais famoso foi apelidado de "Embaixada de Minas Gerais" (1927/28), com a ida de cinco jovens professoras de Belo Horizonte para lá estudarem.

Das reformas educacionais feitas em nome da Escola Nova ou Escola Ativa no Brasil, a mais divulgada, mais comemorada, foi a de Minas Gerais quando Francisco Campos era Secretário do Interior. Ele deu grande ênfase à reformulação do ensino primário, secundário e normal. É difícil explicar como um ideólogo de direita, articulador do golpe do Estado Novo em 1935, que contribuiu para a redação dos Al1 e Al-2 da Ditadura Militar de 1964, esteve ligado a implantação da Escola Nova no Brasil. Ele defendia a ideia de reprimir os excessos da democracia pelo desenvolvimento da autoridade. Nada mais oposto ao ideário da Escola Nova.

Para Campos foi criado, no governo provisório de Getúlio Vargas, o Ministério de Educação e Saúde, ocupado por ele pouco tempo (1930-1932). Francisco Campos foi portanto o primeiro Ministro de Educação do Brasil. Depois exerceu com mão de ferro o cargo de Ministro da Justiça do Estado Novo, período em que liberdades individuais não eram respeitadas e torturas eram praticadas pelo governo. Com a entrada do Brasil na Segunda Guerra Mundial no bloco dos Aliados contra o nazismo e fascismo, Francisco Campos começou a mudar de lado e sua retórica se tornou menos autoritária; com isso conseguiu um lugar na Comissão Jurídica Interamericana, onde atuou até 1955.

O artigo abaixo, que explica muito bem a natureza dos estudos feitos pelas professoras mineiras no TC, me foi dado por uma das professoras da Embaixada de Minas Gerais que estudou no Teachers College - Profa. Alda Lodi - a quem entrevistei acompanhada de uma amiga de adolescência, Vera Chaves. O problema é que o recorte não trazia nem o jornal nem a data da publicação. Ouso desobedecer às regras da ABNT e reproduzi-lo sem referências. 
Desde que o senhor Francisco Campos se tornou secretário do Interior no atual governo de Minas, sua principal preocupação foi reorganizar o ensino público [...].

Dois gestos, entretanto, do atual secretário do Interior de Minas precisam de ser assinalados, porque possuem mais força de ser do que as suas brilhantes exposições de motivos. Um é o convite a professores belgas, suíços e franceses para virem ensinar naquele Estado as lições da escola ativa. E o outro que inspira este artigo, é o de ter enviado, em setembro de 1927, cinco professoras mineiras para se aperfeiçoarem na Universidade de Columbia, em Nova York.

PROFESSORAS MINEIRAS NOS ESTADOS UNIDOS

Essas professoras, que ainda não regressaram ao Brasil, são dd Ignacia Guimarães, Alda Lodi, Amelia Monteiro, Lucia de Castro e Benedita Valladares Ribeiro. D. Ignacia Guimarães já estivera por iniciativa própria em 1922-1924, nos Estados Unidos onde cursara a Universidade George Peabody em Nashville, Tenessee. Era, ao partir de Minas, em 1922, diretora de um grupo escolar da capital; ao voltar, em 1924, foi leccionar metodologia na Escola Normal de Belo Horizonte. Do seu aproveitamento na Universidade George Peabody fala o convite pessoal que recebeu com oferta de uma bolsa de viagem (Macy's scholarship) para continuar seu curso no Colégio de Professoras da Universidade de Columbia ${ }^{10}$.

Devendo, assim, tornar à América do Norte, d.Ignacia Guimarães recebeu do sr. F. Campos a incumbência de conduzir até o Teachers College quatro professoras que ali iriam aperfeiçoar-se. Foi assim que lá foram ter, em setembro de 1927, dd Benedicta Valladares Ribeiro, Lucia de Castro, Alda Lodi e Amélia Monteiro.

Ao chegar em Nova York, essas moças logo deram uma prova de força de vontade. Hospedando-se em um edifício da própria Universidade, destinado à moradia das brasileiras, cada uma foi morar em quarto separado, em andar diferente, passando ali dias sem se encontrarem afim de mais facilmente adquirir a prática da conversação inglesa.

ESPECIALIZAÇÕES

Matriculadas no Colégio de Professores de Columbia ${ }^{11}$, enquanto d. Ignacia Guimarães prosseguia o seu curso universitário, cada uma de suas companheiras resolveu aperfeiçoar ramos da ciência da educação. Assim, d. Alda Lodi se dedicou à aritmética, geometria, desenho e métodos gerais de ensino, especializando-se na organização e direção das bibliotecas escolares.

Esse capítulo das bibliotecas escolares, que tanto tem preocupado os americanos, é para nós de importância primacial. Em matéria de livros didáticos, nossa situação é deplorável. Então para as escolas primárias e normais, o mal do teorismo, sem ciência e sem arte, continua grave apesar das tentativas feitas para remedia-lo. Todos os dias há novos livros aprovados e adoptados pelos conselhos de instrução publica. Mas desses livros raro é o que escapa à falta de graça e de interesse, sem falar nas noções cientificas, erradas ou incompreensíveis, e no descuido artístico, as vezes lastimável. É, talvez, por isso que o sr. F de Campos anda agora empenhado na criação de bibliotecas escolares. E a Associação Brasileira de Educação cuida de rever os nossos livros didáticos.

D. Benedicta Valladares Ribeiro estuda os novos métodos de ensino de Geografia, de Historia e de Moral.

D. Lucia de Castro se dedicou à linguagem, à leitura e à escrita, estudando também problemas sociais relacionados com a escola (SÁ, artigo de jornal cedido por Alda Lodi. Fonte desconhecida).

10 Teachers College que não era só de professoras, mas de professores também.

11 Teachers College. 
Quando entrevistei D. Alda Lodi - uma mulher de modos aristocráticos e hospitalidade mineira - perguntei por que ela fora se especializar em Desenho. O que ela me contou é que arte contaminava todas as atividades do Teachers College. Das professoras que foram na Embaixada de Minas Gerais, a única que ao sair do Brasil já havia decidido ficar um pouco mais e fazer o Mestrado foi Ignacia Ferreira Guimarães. Como comprova a lista dos mestres brasileiros do TC aqui incluída, ela conseguiu terminar o mestrado em pouco tempo.

Em um curso sobre História do Ensino da Arte, uma das minhas orientandas, a mineira Roberta Maira De Melo Araújo, professora da Universidade Federal de Uberlândia, se entusiasmou com a Embaixada de Minas Gerais e a elegeu como tema de seu doutorado; mas terminou por se dedicar à análise de uma das professoras do grupo, Benedita Valladares Ribeiro. Uma das razões é que eu a informei que seu acervo estava cuidadosamente preservado pela filha, Mercedes Valladares Guerra, professora da Universidade Federal de Minas Gerais. Trata-se de um rico arquivo para a compreensão da Educação em Minas Gerais, com muitas cartas de Benedita Valladares escritas para a família quando estava no TC. Selecionei da tese de Roberta Melo algumas cartas que falam especificamente dos estudos no TC; mas a tese ${ }^{12}$ merece ser publicada e lida, pois as cartas são uma magnifica radiografia do que pensava uma jovem de 22 anos, nos anos 1920, acerca dos Estados Unidos e o Brasil, suas surpresas, suas comparações de comportamento, sua crença na educação, suas fantasias e projetos para o futuro, etc.

Benedita Valladares em uma das primeiras cartas se mostra chocada com a repressão ao comportamento das alunas. $O$ imaginário das jovens brasileiras era povoado pela fantasia acerca da liberdade das mulheres nos Estados Unidos, mas ela se decepcionou. Entretanto, o movimento feminista americano era muito ativo e ganhava cada vez mais visibilidade naquele momento, o que Benedita Valladares vai percebendo aos poucos:

O regulamento deste internato, como o de todos os internatos americanos, é muito severo. Há horas de silêncio, horas marcadas para as refeições; se qualquer das moças aqui residentes quer dar um passeio, à noite, e acha que não voltará antes das 10 horas, tem de assinar em um livro, dizendo aonde vai e a que horas volta, e, se passar desta hora, não pode entrar, fica na rua. As moças menores de 23 annos (eu e Lúcia) não podem passear nos Parques

12 ARAÚJO, 2010. 
Riverside Drive e Morning side Drive, depois do anoitecer, e não podem ir na Coney Island e outros parques de diversões, nem mesmo durante o dia, sem a companhia de um homem. E eu que imaginava que aqui a mulher, em todo e qualquer logar, podia prescindir do homem. Estou desilludida!... Não é permittido também fumar. Se uma moça (menor de 23 annos) quer dar um passeio em companhia de um homem, precisa pedir licença à directora social (Miss Brown) e dizer onde vai. Há muitas outras regras ainda, muito interessantes [grifo meu] (Ribeiro apud ARAÚJJ, 2010, p. 67).

Em outra carta, 14 dias depois já havia percebido que o rigor não era tão drástico:

O boato, que ocorreu a meu respeito, de que eu não poderia andar desacompanhada, nem mesmo dentro do Whittier não é verdadeiro, ou, por outra, é muito exaggerado... Há, de facto, aqui, um regulamento que prohibe as moças menores de 23 anos sahirem sozinhas; mas é só...para inglêz ver. Miss Brown (é a directora social) disse-me, um dia, em conversa, que não acha conveniente que uma mocinha vá sozinha, à cidade (down town), mas que 2.está muito direito. De forma que, quando tenho que ir á cidade, arranjo uma companhia, tenho ido ao cinema, umas 2 ou 3 vezes, só com a Lucia, e não há inconveniente nenhum as moças todas andam sozinhas; como já me disseram a sra. do dr. Sampaio e muitas outras pessoas. A mulher aqui tem os mesmos direitos e a mesma liberdade, quase, que o homem! Aqui perto ando sozinha. Vou ao Banco, faço umas comprinhas... sem dar satisfação a ninguém (Ribeiro apud ARAÚJO, 2010, p. 67-68).

Sua percepção para as conquistas sociais e os direitos das mulheres foi se desenvolvendo. Já sobre a questão dos negros, nas cartas transcritas por Roberta M.M. Araújo, há apenas uma menção:

\begin{abstract}
Vou passar uma semana muito divertida...e trabalhosa. $O \mathrm{dr}$. Del Manzo organizou, para o nosso curso de Comparative Education, uma excursão, a diversas cidades norte-americanas, para visitarmos escolas de todos os typos: normaes, secundárias e profissionais, primárias, rurais etc. As despesas das passagens e hotéis são feitas pelo International Institute. Temos que pagar apenas as nossas refeições.

Partimos amanhã, à tarde, para Baltimore em trem de ferro. Ficaremos nesta cidade 4 dias, visitando não sei quantas escolas. Seguiremos, depois, para Washington, onde permaneceremos 2 dias (...) iremos a Hampton, no Estado de Virginia, em um vapor. Diz o dr. Del Manzo que esta parte da viagem é muito bonita. Ahi visitamos o Hampton Institute, a $1^{\text {a }}$ escola profissional dos E. Unidos, apezar de ser para negros. (É uma escola agrícola e industrial, tendo também um curso normal, para preparar professores para a escola de negros, no Sul) De Hampton iremos a Philadelphia e, no dia 9, à noite, estaremos de novo aqui (Ribeiro apud ARAÚJO, 2010, p. 73).
\end{abstract}

O Hampton Institute foi uma das primeiras escolas universitárias para negros nos Estados Unidos. Viktor Lowenfeld nos anos 40 dirigiu o Departamento de Arte daquela instituição - que hoje se chama Hampton University. Ele, por ser judeu da Áustria que viveu em um país dominado pelos nazistas, conhecia a dor da perseguição racial. Sempre foi muito solidário com a luta dos negros nos Estados Unidos. Como 
arte/educador ele se empenhou em tornar a arte elemento central da educação naquela instituição. É importante notar a política do TC de levar estrangeiros ao Hampton Institute - vitrine da educação dos afrodescendentes, cuja alta qualidade não era o suficiente para perdoar a segregação, mas dava boa impressão.

Continuando, esta carta diz:

É provável que, em Washington, estejamos com o Presidente Coolidge. Por falar nisto, no dia 8 vai haver eleições. Gostaria de estar aqui no Whittier Hall para ver como é que as americanas votam e se levam a sério esta questão. Diz Miss Diller que, em Philadelphia, onde estaremos no dia 8, é muito interessante a eleição, e vou ver se consigo ver as mulheres votando (Ribeiro apud ARAÚJO, 2010, p. 74).

O interesse quase testemunhal de Benedita Valladares pelo voto feminino se explica pelo fato de que as mulheres não votavam no Brasil; só começaram a votar em 1934. Era como se ela esperasse uma modificação qualquer nas mulheres que votavam. E tinha razão; o sentimento de dignidade muda as pessoas. Fico fascinada com a curiosidade, a inteligência e a capacidade de renovar as ideias desta jovem mineira nos anos 20.

Uma das coisas que ela admirava era a capacidade dos americanos criticarem sua própria cultura e política. Kilpatrick para ela era um dos mais críticos. Conheci o método de projetos de Kilpatrick - um excelente tradutor das ideias de Dewey para a prática cotidiana das escolas - nas aulas de Paulo Freire, ainda no início dos anos 60 no Recife.

[...] Dr. Kilpatrick há poucos dias disse em aula - que a milhares de americanos que nunca viram e nunca verão, já não digo um paiz estrangeiro mas, nem ao menos, as fronteiras do seu próprio paiz. V. pode comprehender como é possível que no meio de tanta civilização, elles sejam tão ignorantes do resto do mundo, tão indifferentes ou adversários mesmos - e é isto que eu chamo de provincianismo [...]lnflue tambem - e muito - para isto, o facto do americano ser, no geral, tão materialista, tão pouco dado a leituras. Elle se deixa levar pela vida intensa, pela ansia por dinheiro e conforto material que, aqui são os objectivos de quase todo o mundo, a não ser jornais e livros americanos (Ribeiro apud ARAÚJO, 2010, p. 78).

Insiste na capacidade crítica de Kilpatrick:

Há dias, conversamos [Benedicta e sua amiga Miss Jane] a respeito dos E. Unidos (o que originou a conversa foi o Dr. Kilpatrick ter dito em aula que os E. Unidos é actualmente o paiz mais 'disturbing' do mundo) e ella repetiu, com muita graça o que sua amiga inglesa dizia dos americanos que vão à Europa, nos 'tours' de verão...Diz ella, a amiga ingleza, que os americanos 
quando visitam um monumento de arte ou um castelo antiquíssimo da Europa, soffrem sempre um desillusão e dizem: Oh! Mas que cousa pequena, baixa! Na minha terra as casas são altas, altíssimas! Em New York, há casas com muitos andares!

Este provincianismo impressiona muito os americanos que não o são e especialmente os educadores (só os leaders, naturalmente). Não há, creio, logar nenhum no mundo em que se fale tanto em 'better understanding of other people', em 'international understanding and friendship'! ... Parece até uma ironia! Como disse o Dr. Del Manzo, um dia nós só falamos no que não temos... Dr. Kilpatrick, Dr. Rugg, Dr. Johnson, Miss Reed não passam quasi uma aula sem se referirem a isto! $E$ todos os outros professores também. Dr. Kilpatrick e miss Reed falam, porém, de modo a quasi irritar os americanos! Dr. Kilpatrick contou-nos o caso de uma pequenina japonesa que ouviu, muitas vezes, em casa, referencias à lei americana que prohibia a entrada dos orientaes no território americano; aconteceu que nesta mesma ocasião uma escola americana enviou à escola que esta menina frequentava uma boneca (é costume aqui fazerem as creanças dos diferentes paizes enviarem presentes umas para as outras, com 0 fim de desenvolver 'better understanding of other people')...A japonezazinha, ouvindo os paes se referirem à América com ódio e rancor, e, ao mesmo tempo, vendo a boneca enviada pelos americanos, ficou sem saber o que pensar, e, um dia, afinal. Disse: Odeio a América, mas amo os americanos! Coitado do Dr. Kilpatrick! Contou esta história com emoção! E acrescentou: Os srs. não veem que esta lei foi insultar a milhões de indivíduos e que todos estes indivíduos hoje nos odeiam?! E depois disse: São leis semelhantes a estas que estão fazendo com que o nosso paiz esteja ficando cada vez mais odiado no estrangeiro e o resultado é que se não mudarmos de 'policy', o mundo todo talvez se ligue um dia contra elle! (os E. Unidos). (...) Algumas americanas ficaram indignadas em ouvi-lo falar assim! (Ribeiro apud ARAÚJO, 2010, p. 80).

Outro aspecto do Teachers College que Benedita Valladares admirou foi a possibilidade de os professores divergirem, sustentarem diferentes teorias e socialmente conversarem pacificamente. Agora, em pleno século XXI, quase cem anos depois da experiência de Benedicta, isso é impossível no ensino da arte no Brasil: poucos discutem posição teórica e todos pontificam. A luta pelo poder dentro e fora das universidades, concursos de ingresso na carreira, bolsas, visibilidade em congressos, trânsito em editoras e cargos governamentais, está levando professores a quererem e fazerem o possível para acabar com os que não pensam igual - e até acabar com a própria arte na escola se isto der prestígio. Não há divergência intelectual: há guerra, formação de quadrilha para as bancas de concurso, e os jovens é que sofrem, pois não podem ser independentes, são pressionados a se aliar a este ou aquele grupo.

[...] divergência de opinião entre os professores, é uma das características do Teacher's College. Do mesmo modo, os alunos têm pleno direito de discordarem e discutirem com os professores, tanto quanto quiserem; não resultando nenhum desaffecto, em nenhum dos 2 casos. Em relação aos social studies, há aqui 2 grupos: um, que pensa que as matérias que constituem mais especialmente os social studies- geog., historia+ civics - 
devem ser ensinadas separadamente nos upper grades- $4^{\circ}, 5^{\circ}, 6^{\circ}$ e high school.

[...] dr. Rugg é considerado o chefe dos que pensam que as matérias que constituem os "social studies" devem ser estudadas conjuntamente, no mesmo período. Rugg vae mais longe do que nenhum outro- elle não admite horários na escola primária, todo o ensino gira em torno dos chamados centros de interesse (ou projects), envolvendo, ao mesmo tempo, o ensino de todas as matérias. Acho a sua ideia (semelhante à de Decroly) teoricamente magnifica, mas duvido que possa ser aplicada nas escolas públicas, com o 'average' teacher). Miss Read também pensa como eu [...] Rugg garante que o methodo pode ser adaptado nas escolas públicas; não conheço ainda os argumentos em que elle se baseia para affirmar isto. Só depois de conhecer ambos os lados, é que poderei ter uma opinião definitiva [...]. Além disto, pretendo visitar mtas escolas, agora que já não tenho nenhuma dificuldade em entender o inglez e que já sei, mais ou menos, distinguir numa escola ou methodo bom ou um ruim, Na escolha dos cursos, arranjei tudo de modo a ter 2 dias livres na semana, só para poder observar o maior tempo possível na Horace Mann e visitar outras escolas, particulares e publicas (Ribeiro apud ARAÚJJ, 2010, p. 85-86).

Este debate sobre Estudos Sociais viemos ter aqui no Brasil durante a ditadura militar, mas ele foi mais político que teórico. Naquele ano de 1928 o professor Harold Rugg havia publicado com Ann Shumaker o livro The Child-Centered School, baseando as ideias sobre o ensino da arte no trabalho que Florence Cane fazia na Walden School. ${ }^{13}$ As cartas de Benedicta falando das aulas da Escola Horace Mann - escola laboratório ou de demonstração do Teachers College - são longas e muito interessantes, mas estou economizando a citação das cartas para que a tese de Roberta ao ser publicada cause impacto. Só não resisto a comentar mais dois trechos das cartas:

\begin{abstract}
Apezar de não ter ainda estudado a pedagogia do desenho, tenho uma ideia de como o ensino é feito aqui, ideia esta baseada nas aulas de desenho que tenho assistido na $\mathrm{H}$. Mann e nas conversas sobre o assumpto que tenho tido com a Fanny (a minha amiga). A ideia que tenho é que o ensino aqui é "espontâneo", bastante semelhante ao do dr. Nereu. Espantou-me muito, por isto, ler na carta da Luiza que não é este o systema preconizado pelo Classroom Teacher. Vou examinar esta questão ${ }^{14}$ (Ribeiro apud ARAÚJO, 2010, p. 87).
\end{abstract}

Realmente a metodologia usada por Nereu Sampaio, a quem Benedita Valladares se refere, era inspirada em John Dewey, mas em seus primeiros livros como Educação e Sociedade - no qual as recomendações eram mais naturalistas, tornando-se o desenho de observação o único estímulo para a expressão da criança.

\footnotetext{
13 Informação dada por Arthur D. Efland (1990).

14 Benedicta Valladares Ribeiro apud ARAÚJO, 2010, p. 87.
} 
Logo que entrou no TC, Dewey, mais maduro, aceitava e estimulava os métodos de Arthur Dow que promoviam o desenvolvimento da percepção e criação, mas davam alguma instrução; inclusive buscava desenvolver a apreciação da arte. Alguns viam o mútuo apoio entre Dow e Dewey como estratégia política de sobrevivência e não concordância teórica. Frederick $\mathrm{C}$. Moffatt ${ }^{15}$ afirmou que a união dos dois visava vencer o medo dos inimigos: de um lado os acadêmicos da teoria da arte e do lado oposto os diluidores da arte sob pretexto do ensino prático. Segundo Moffatt, para Dow o agente central da aprendizagem era o professor, e a mente o mais importante receptor; já para Dewey seria o aluno o principal agente, e os sentidos os receptores privilegiados da aprendizagem. Quando Benedicta Valladares esteve no Teachers College, Dow já havia morrido (1922) há sete anos, e muitas das práticas defendidas por ele já começavam a mudar no TC sob a influência de Harold Rugg professor de Benedicta que era mais expressionista e que discordava dos ensinamentos de Dow. A jovem Benedicta percebeu essa tendência a um mais radical espontaneísmo da Escola Horace Mann. The Classroom Teacher do qual Benedicta está falando na citação acima era um livro didático em 12 volumes, publicado em 1927-28 por Milo B. Hillegas (editor-in-chief), Thomas H. Briggs (editor, junior-highschool section) e 60 outros importantes educadores, com a introdução do Diretor do Teachers College, William L. Russell. Na área de arte oscilava e pendia mais para a influência de Dow do que para o expressionismo.

O mesmo entusiasmo que Benedicta Valladares teve com a educação para professores do Teachers College era partilhado por Jane Betsey Welling, quando aluna de graduação do TC, curso que iniciou em 1913. Contudo, voltou ao TC para fazer Mestrado e Doutorado em 1929, ano em que Benedicta deixou o TC. Em manuscrito publicado por Peter Smith diz:

Quando retornei para minha "alma mater" em torno de 1929 para fazer o mestrado eu tinha me tornado um numero em uma cadeira. Ninguém sabia meu nome exceto os documentos. Ninguém se importava se eu em carne e osso estava lá ou não.Toda informalidade fora embora. O método expositivo para grandes grupos estava em plena ascensão. As notas e testes eram anunciados por números. Ninguém conhecia ninguém, nem muito de qualquer coisa, exceto as rotineiras. As aulas expositivas eram sobre como e o que ensinar (Welling apud SMITH, 1996, p. 129).

15 MOFFATT et al., 1977, p. 109. 
Betsy foi uma das muitas mulheres na art education norte-americana que foram muito influentes no seu tempo, mas apagadas pela História apesar de terem escrito vários livros - alguns usados nos cursos de formação de professores ao longo de muitos anos. O livro de Peter Smith que traz esse depoimento tem mais quatro capítulos sobre a cegueira acerca da colaboração das mulheres na Arte/Educação: isto é o preconceito de gênero, problema para o qual as arte/educadoras do Brasil ainda não acordaram, ou então não estariam sendo tão docilmente manipuladas por alguns homens que penetraram nas universidades do planalto central e estão inspirando outros homens em outras universidades as táticas da dominação Eles, ao mesmo tempo autoritários e sedutores, proíbem que o alunado - formado principalmente de mulheres - leia e cite este ou aquele livro e as constrangem a citar o que eles próprios escrevem. Perseguiram atrozmente uma jovem e inteligente professora que queria trabalhar com diferentes linhas de Arte/Educação, a ponto de obrigá-la a mudar de unidade universitária, mudar seu objeto de estudos e o rumo de sua carreira. Não precisavam disto para ganhar poder, mas ela se constituiu em instrumento para demonstrar este poder Também não precisavam instituir uma falsa batalha a favor da Cultura Visual que já vinha se incorporando ao ensino da arte no Brasil. Foi uma batalha encenada como marketing para uma guerra já vitoriosa.

A divergência de opiniões sobre o TC entre Benedicta e Betsy tem que ver com os diferentes contextos das duas alunas e com a diferença dos cursos que comentam. Nos Estados Unidos dos anos 70, quando fiz meu mestrado e doutorado naquele país, os cursos de graduação para professores - ou licenciatura, como chamamos aqui eram mais orientados para a construção de uma prática, e os mestrados e doutorados mais formais e intelectualizados. Um dos meus melhores professores do Doutorado da Boston University nos disse que uma disciplina de pós-graduação que não exija dos alunos pelo menos a leitura de nove páginas por dia, inclusive fim de semana, não seria uma disciplina ministrada por um professor sério. Portanto para cada disciplina um aluno deveria ler 1350 páginas. O curso que Benedita comentava tão positivamente era de Formação de Professores e o que Betsy estava fazendo e criticando negativamente era de Mestrado.

Por último, cito algumas linhas de uma carta de Benedicta que Roberta transcreve em sua tese: 
Tenho a impressão que o dr. Antônio Carlos está dando um grande impulso a instrucção. Todos os no do Minas que me chegaram às mãos quase só falam em escola, em professor. Só no de 4 de abril vem a creação de 370 escolas rurais! Fiquei enthusiasmada! Estou com vontade de mostrar este Minas ao dr. Handel, que vive a falar que todos os paizes da América do Sul precisam imitar o México (Ribeiro apud ARAÚJO, 2010, p. 79).

Curiosamente ela elogia o governador de Minas Gerais da época - um democrata liberal - e não o seu Secretário Francisco Campos, que ano após ano foi se tornando um político cada vez mais autoritário. Sempre me perguntei como Francisco Campos, um político repressor e ditatorial, se empenhou tanto para trazer a Escola Nova para seu Estado. A carta de Benedicta responde à pergunta: era a vontade política do Governador Antônio Carlos Ribeiro de Andrada, que comandava o seu Secretário do Interior em direção à defesa da Escola Nova ou Escola Ativa. Comprovando sua ideologia democrata, Antônio Carlos abandonou a política no início do Estado Novo por abominar ditaduras, enquanto Francisco Campos tornou-se o político poderoso do Estado Novo ditatorial. Quanto ao México ser invocado como modelo de boa educação pelo Prof. Handel, ele tinha razão: depois da Revolução de 1910 eles avançaram muito em educação. As Escuelas al Aire Libre foram um exemplo desse avanço. Em ensino de arte não havia nada mais avançado nos Estados Unidos em 1928.

Por último quero lembrar que a biblioteca do TC é uma das melhores do mundo sobre Educação no Brasil dos anos 20 aos anos 50. Pesquisei em várias bibliotecas estrangeiras excelentes para os estudos latino-americanos, como a Biblioteca do Congresso em Washington; a Biblioteca do Instituto Ibero-Americano em Berlim; a Coleção latino-americana Nettie Lee Benson, conhecida como Biblioteca Latinoamericana da Universidade do Texas em Austin; e as bibliotecas da Universidade de Yale - mas sobre educação dos anos 20 até o fim do Estado Novo a do TC é a melhor. Continuo pedindo aos meus amigos que vão estudar no Teachers College que me enviem o xerox deste ou daquele livro antigo. Tenho um caderno com os títulos e números dos livros nas estantes que não consegui ler, mas continuam me interessando ${ }^{16}$.

${ }^{16}$ Fui Fulbright Fellow no Teachers College de dezembro de 1991 a junho de 1992. 
A História da Arte/Educação do Teachers College teve altos e baixos. No fim dos anos oitenta quase fecharam o Departamento de Art Education. Mas resolveram fazer mais uma tentativa e contrataram para dirigi-lo Judith Burton, pesquisadora e professora inglesa que ensinava na Boston University. Ela não só renovou o departamento, mas em 2012 podemos dizer que o tornou a mais importante PósGraduação em Art Education de Nova York. Um dos trunfos de Burton é se manter fiel à pesquisa e não cair em dogmatismos da moda. Foi muito crítica dos exageros do Discipline Based Art Education - movimento financiado pelo J. P. Getty Trust - assim como da hegemonia da Cultura Visual que se seguiu. Ela veio ao Brasil dar um curso no Museu de Arte Contemporânea da USP, ao mesmo tempo em que Monique Brière - canadense, autora de livros didáticos ligados ao movimento DBAE. Burton havia publicado com Arlene Lederman e Peter London em 1988 o livro Beyond DBAE: the case for multiple visions of art education ${ }^{17}$.

Muitos alunos fizeram os dois cursos e vinham me reclamar que eram posições antagônicas. Mas eu, que as convidei, queria isso mesmo: que ouvissem os dois lados e refletissem - uma prática implementada no Teachers College desde sua criação, que foi percebida pela jovem mineira Benedicta Valladares Ribeiro em 1928.

\section{Referências}

A MELHOR APROXIMAÇÃO ENTRE O BRASIL E OS ESTADOS UNIDOS: Chega hoje á noite, pelo "Western World" a segunda turma de professores norte-americanos. Diário de Notícias. Rio de Janeiro. 10 jul. 1930.

ARAÚJO, Roberta Maira de Melo. Benedicta Valladares Ribeiro (1905 - 1989): formação e atuação. 2010. 221 f. Tese (Doutorado em Artes) - Escola de Comunicações e Artes, Universidade de São Paulo, São Paulo. 2010.

BOAS, Belle. Art in the School. New York: Doubleday/Page \& Company, 1926.

BURTON Judith M.; LEDERMAN, Arlene; LONDON, Peter. (Eds.) Beyond DBAE: the case for multiple visions of art education. New York: University Council on Art Education, 1988.

CARVALHO, Delgado de et al. Ampliando os horizontes da nossa cultura: a Associação Brasileira de Educação está cogitando de enviar anualmente 10 professores brasileiros para visitar as universidades americanas - diz-nos em entrevista, o professor Delgado de Carvalho. Jornal do Brasil. Rio de Janeiro. 05 jul 1929.

EFLAND, Arthur D. A history of art education: intellectual and social currents in the teaching visual arts. New York: Teachers College Press, 1990.

MATHIAS, Margaret. The begining of art in public schools. New York: Scribner, 1924.

\footnotetext{
17 BURTON, Judith M. et al., 1988. O título é uma ironia com o primeiro livro editado pelo J. P. Getty Trust acerca do DBAE intitulado Beyond Creating: the Place for Arts in America's Schools (1985).
} 
MOFFATT, Frederick C. et al. Arthur Wesley Dow, 1857-1922: his art and his influence. Washington: Smithsonian Institution Press, 1977.

OKASAKI, Akio. Dow's conception of teaching art: "harmonious composition" and "Notan". In: INSEA WORLD CONGRESS, 30, 1999, Brisbane/Australia. Anais... Brisbaine, 1999.

SÁ, Carlos. Minas no colégio de professores da Universidade de Columbia. Artigo de jornal cedido por Alda Lodi. Fonte desconhecida. S/d.

SAUNDERS, Robert J. A history of the teaching of art appreciation in the public schools. In: ECKER, David (Org.). Improving the teaching of art appreciation. Columbus/Ohio: Ohio State University Research Foundation, 1966.

TEIXEIRA, Anísio; GOÉS FILHO, Joaquim Faria. A tradição da Fundação no campo dos estudos das Ciências Sociais. Rio de Janeiro: Fundação Getúlio Vargas, 1971.

SMITH Peter. The history of American Art Education: learning about art in American schools. Connecticut: Greenwood Press, 1996.

\section{Ana Mae Barbosa}

Possui graduação em Direito pela Universidade Federal de Pernambuco (1960), mestrado em Art Education pela Southern Connecticut State College (1974) e doutorado em Humanistic Education pela Boston University (1978). Atualmente é professora titular aposentada da Universidade de São Paulo e professora da Universidade Anhembi Morumbi. Foi presidente da International Society for Education through Art (InSEA), da Associação Nacional de Pesquisadores em Artes Plásticas (ANPAP) e diretora do Museu de Arte Contemporânea da USP. Tem livros e artigos publicados em diversos países. Tem experiência na área de Artes, com ênfase em Arte/Educação, atuando principalmente nos seguintes temas: Ensino da Arte e contextos metodológicos, História do Ensino da Arte e do Desenho, Ensino do Design, Administração de Arte, Multiculturalidade, Estudos de Museus de Arte e Estudos Visuais.

E-mail - anamaebarbosa@gmail.com

Currículo - http://lattes.cnpq.br/1650414096296319 